\title{
Die Konsep Ontwikkeling: Opvattings en Teorieë
}

N. J. J. OLIVIER

Dept. Romeinse Reg, P.U. vir C.H.O.

\begin{abstract}
The aim of this essay is to give a brief discussion of the changing interpretations of the concept development. In the years following the Second World War an indiscriminate and uniform attitude concerning development - that can best be summed up in the words: food for one must be food for all - existed. During the Sixties, the era of positivism and high capitalism, two schools of thought branched out. The Social Sciences Research Council emphasised political development. The Comparative Administration Group, on the other hand, emphasised the output function of development, "the implementation of development programmes, or the transformation of dreams into concrete development practice".
\end{abstract}

Since the Seventies a new anti-positivistic trend has emerged. The co-ordinates of this new revolution are relevance and dynamism. Intermediate (appropriate) technology is deemed to be of paramount importance, and the "development for what" - question (in terms of which the ratio for development has to be determined) is emphasized. Relativity and the improvement of the quality of life are deemed to be important premises.

From the original evolutionary development theory three theories evolved: the limits to growth modeh the so-called ambiguous development theory, and the development of underdevelopment model The last theory (which in South America is often described as the dependencia theory) is in Neo-Marxist thought the only acceptable explanation for the dichotomy rich-poor. Christian writers on development seem to accept the following definition: Development is to do more, to know more, to have more in order to be more.

Die ontwikkeling van agtergeblewe gebiede en gemeenskappe het sedert die Tweede Wêreld oorlog sterk op die voorgrond getree. Ook Suid-Afrika se nasionale beleid het grootliks 'n ontwikkelingsbeleid geword. Oor die konsep ontwikkeling bestaan daar egter wyd uiteenlopende menings. Die doel van hierdie studiestuk is om op kursoriese wyse die verskillende benaderinge met betrekking tot sowel die omskrywing van, as die teorieë omtrent die konsep ontwikkeling aan die hand van resente literatuur saam te vat. Die metode wat gevolg sal word, is om eerstens Fick (1979) se oorsig van die benaderingsveranderíngs tot die konsep ontwikkeling te bespreek. Tw'eedens sal daar na 'n aantal ander skrywers verwys word. Ten slotte sal as samevatting 'n aantal kenmerke van ontwikkeling aangedui word.

Koers, 46 (2) 1981 


\section{Die konsep on twikkeling}

Die konsep ontwikkeling was aanvanklik nie teoreties gefundeer nie. Die ontwikkelingsbewustheid van die vrye wêreld, besonderlik ten opsigte van die Derde Wêreld het bloot van die standpunt uitgegaan dat ontwikkeling oral dieselfde is wat betref doelwitte, prosesse en formules. Dié benadering word goed saamgevat in die gesegde: "food for one must be food for all". Eers in die sestigerjare het daar verskillende teorieë oor ontwikkeling begin ontstaan en sedertdien het daar belangrike veranderinge in die aard, inhoud en betekenis van die konsep ontwikkeling plaasgevind (Fick, 1979:172).

\section{ONTWIKKELINGSTEORIË̈ TY DENS DIE SESTIGERJARE}

Die positivisme - met die tese dat wetenskaplike kennis die enigste geldige kennis is en dat feite die enigste moontlike objek van dié kennis is - was dié filosofiese stroming onderliggend aan die benaderings met betrekking tot ontwikkeling tydens hierdie tydperk.

Fick (1979:174-179) maak 'n onderskeid tussen die

- sosiale positivisme waarvolgens die menslike verstand dieselfde struktuur as die natuurgegewe feite het, en dus ewe voorspelbaar is: hiervolgens is menslike gedrag voorspelbaar. Dié stanpunt is deur filosowe soos Comte, Bentham en John Stuart Mill gehuldig;

- evolusionêre positivisme wat ingehou het dat daar 'n enkellynige evolusie van minder beskaafd na beskaafd - analoog aan biologiese evolusie bestaan. Spencer was een van die voorstanders van hierdie benadering; en die

- logiese of neo-positivisme wat vereis dat alle wetenskaplike stellings verifieerbaar moes wees.

Die positivistiese onderbou was een van die vernaamste stimuli vir die ontwikkeling van die behavioralisme tot die dominante benadering tot die studie van die politiek in die sestigerjare. ' $n$ Ander belangrike impetus was die beklemtoning van sosiale aksie deur die Duitse sosioloog Max Weber. Die Weberiaanse sosiologie sowel as die behavioralisme het 'n belangrike invloed gehad op die bekende staatkundige, David Easton, wie se sisteemteorie van die politiek nou nog wye aanvaarding geniet. Volgens hierdie teorie word 'n politieke stel- 


\section{N. J. J. Olivier}

sel onder andere gekenmerk deur insette ("inputs") en uitsette ("outputs"). Dié benadering is oorgeneem deur twee groepe skrywers oor die Ontwikkelingsadministrasie, die Social Sciences Research Council (SSRC) en die Comparative Administration Group (CAG).

Die Social Sciences Researcb Council (SSRC) is in 1963 gestig en het politieke ontwikkeling vanaf die insethoek beskou. Hulle vernaamste vrae was watter invloed faktore soos kommunikasiemiddele, burokrasie, onderwys en politieke kultuur op die politieke stelsel sou kon hê. Hulle het 'n sogenaamde "crises and sequences model of political development" geformuleer, welke model voorsiening gemaak het vir 'n ontwikkelingsindroom waarvan menslike gelykheid, kapasiteit (die elite se vermoë om op kreatiewe en rasionele wyse eise wat an die regering gestel is, te akkommodeer) en organisatoriese differensiasie die koördinate was.

Volgens die SSRC is daar ses ontwikkelingskrisisse of nasieboukrisisse wat deur politieke sisteme hanteer moet word (La Palombara 1971:27-66):

1. Die identiteitskrisis. Dit behels twee fasette:

* die mate waarin die individu in staat is om van die meer parogiale (stam-die mate lojaliteite) en tradisionele na die meer moderne en kosmopolitaanse gesteldheid te beweeg; en

- die groep waaraan die individu hom nou gebonde ag (plattelandse of stadsgroep), en die politieke eenheid waaraan hy hom by wyse van oorheersende lojaliteit verbind (bv. Kenia an of Kikuyu).

2. Die legitimiteitskrisis. Dit behels die mate waarin die regeringsubjekte glo dat die maghebbers en die staatinstellings wettig behoorlik en aanvaarbaar is.

3. Die penetrasiekrisis. Dit behels die vraag of die sentrale regering by magte is om die regeringsbeleid ook in die verste uithoeke van die land toe te pas. Dit behels dus ' $n$ uitdaging aan die regering se organisatories-administratiewe vermoëns.

4. Die deelnamekrisis. Dit behels die vraag wie an die politieke proses wil deelneem, boe en waarom. 
Die konsep ontwikkeling

5. Die integrasiekrısis. Dit het betrekking op die probleme van geografiese integrasie en psiologiese integrasie.

6. Die distribusiekrisis. Dit behels die vraag wie watter gedeelte van die bronne wat deur die sentrale regering gedistribueer word kry. Dit gaan dus oor die verdeling van tegniese dienste soos paaie en onderwys, en oor die ideologiese grondslag van die wyse waarop die beskikbare hulpbronne onder die bevolking verdeel word.

Die besondere ontwikkelingspatroon in enige gegewe land word hoofsaaklik deur die volgorde waarin hierdie krisisse na vore kom en die wyses waarop hulle hanteer word, bepaal. Dit het onder andere gelei tot die bestudering van die vraag hoe die verskillende omgewingsfaktore gemanipuleer kan word om sodoende die politieke stelsel te laat ontwikkel.

Belangrike outeurs in hierdie verband was Almond, Pye, La Palombara, Coleman, Verba en Binder.

Die Comparative Administration Group (CAG) is ook in 1963 gestig en het meer klem op die uitsetfunksie geplaas. Die vermoë van die politieke stelsel om effektiewe ontwikkeling in sy gebied aan te bring, is beklemtoon. Fick (1979:177) stel dit so: "The implementation of development programmes, or the transformation of dreams into concrete development practice, thus became the main focus of this group."

As tweede kenmerk van die sestigerjare-benadering noem Fick (1979:177-178) die positivistiese ekonomiese beskouing waarvolgens definitiewe en onafwendebare groeifases waardeur elke ontwikkelende gemeenskap moes gaan, geidentifiseer is. So onderskei Rostow (1971) vyf fases:

- die tradisionele samelewing;

- voorvereistes vir "take-off";

- "take-off" (dıe belangrikste stadium; duur ten minste twintig jaar);

- die "drive to maturity"-fase (ten minste 40 jaar); en ten slotte,

- die tydperk van "high mass consumtion".

Volgens Baldwin (1972:72-80) volg dit uit Rostow se benadering dat landboumodernisering ' $n$ voorvereiste vir industriële ontwikkelingspogings is; daarenteen is sy eie mening dat die landbou- en industriële sektore saam uitgebou moet word. 


\section{J. J. J. Olivier}

Die belangrikste outeurs in hierdie groep was Braibanti, Riggs, Essman, Waldo en Weidner.

Samevattend word die ontwikkelingsteorieë van die sestigerjare deur die volgende gekenmerk:

- Die dominante invloed van die positivisme het neerslag gevind in die behavioralistiese benadering (met sy beklemtoning van die sisteemanalise en die struktureel-funksionele teorie) en die ideaal van 'n waardevrye wetenskap;

- 'n anti-historiese benadering;

- 'n voorkeur vir kwalifisering en matematiese formulerings;

- die gebrek aan 'n algemene teorie van politieke ontwikkeling.

\section{POLITIE KE ONTWIKKELINGSTEORIEE VAN DIE 1970's}

Vanuit die sosiologie het daar 'n reaksie teen die behavioralisme na vore getree. Die koördinate van die nuwe revolusie is relevansie en dinamiese handeling, wat wesenslik anti-positivisties van aard is. Die uitgangspunte van hierdie postbehavioralisme word deur Fick (1979:181) soos volg opgesom:

- ". . . it is better to be vague than non-relevantly precise";

- waardevrye wetenskap moet vir waardeoordele as premisse plek maak; en

- wetenskaplikes moet by die huidige sosiale vraagstukke betrokke wees en sodoende aan die herskepping van die gemeenskap deelneem.

Hierby moet gevoeg word die aanvaarding van die historiese, wat die kontekstuele inagneming van die rol van waardes in die gemeenskap behels.

Derdens het ekonomiese beskouings ook begin verander. Ka pitalisme as einddoel van ontwikkeling word nie langer sonder meer aanvaar nie, en dus word aspekte soos kapitaalvorming minder beklemtoon. Dit het onder andere tot 'n groter Klem op toepaslike of intermediêre ("appropriate" of "intermidiate") tegnologie - die verinheemsing van ontwikkelingstegnieke - gelei. Volgens Castle (1972: 57) moet tegnologieë vir elke besondere ontwikkelingsituasie toepaslik gemaak word.

In die vierde plek verwys Fick (1979:183-187) na die sogenaamde "Development for what?"-vraag. Hierdie vraag impliseer die volgende: 
Die Konsep Ontwikkeling

- Onderontwikkeldheid sou eintlik 'n gevolg van ontwikkeling (in die ontwikkelde lande) wees: so ontstaan die sogenaamde "dependency theory"

(afhanklikheidsteorie). Volgens sommige skrywers kan dié wantoestand slegs reggestel word indien die minder ontwikkelde Derde Wêreld-lande kartelle vorm om sodoende hoër pryse vir hulle minerale te verkry: soos byvoorbeeld die OPECkartel.

- As tweede implikasie is die vroeëre eenlynige benadering ten gunste van ' $n$ waarde-georiënteerde grondslag vir ontwikkeling verwerp. Veral Goulet (1977) het die soeke na ' $n$ waardebasis vir ontwikkeling beklemtoon. Reeds in 1973 het die Amerikaanse Kongres die vroeëre etnosentrisme (wat in feite op Amerikaanse kulturele en ideologiese imperialisme - dat die Amerikaanse "way of life" die uiteindelike doelstelling moes wees - neergekom het) laat vaar; die ontwikkelingshulp moes voortaan bloot ter "improving the lives of the poorest of the people" aangewend word. Die erkenning van kulturele relatiwiteit is een van die gevolge van hierdie nuwe benadering. Goulet (1977: 249-272) meen dat daar drie kardinale waardevrae ten grondslag van ontwikkelingshulp lé:

* Kan wêreldarmoede uitgewis word? Ontwikkelingsbeleid behoort syns insiens slegs $d i t$ (die uitwissing van armoede en nie die verkryging van rykdom nie) ten doel te hê;

* Is wêreldwye soberheid noodsaaklik? Goulet $(1977: 263)$ antwoord soos volg: "Without massive austerity, imposed and voluntary, human concern for the genuine needs of other men cannot survive."

* Kan kulturele diversiteit nieteenstaande toenemende standaardisasie gered word? $\mathrm{Na}$ sy mening moet dit as teenwig vir die kragtige werking van die standaardisasie wat inherent aan die modernisasieproses is, dien en daarom moet dit beklemtoon word.

Dit gaan dus vir Goulet in ontwikkeling om verbetering van die lewensgehalte. Politieke ontwikkeling (byvoorbeeld deelname an 'n demokrasie) beteken syns insiens op sigself niks. Die woorde van Pous Paulus VI druk dit soos volg uit: "Development is to do more, to know more, to have more, in order to be more."

- Die aanvaarding van kulturele relatiwiteit bring egter nie noodwendig mee dat daar geen universalia is nie. So verklaar Goulet (1977:86-95) dat 'n onderskeid tussen kulturele absoluutbede (wat binne 'n bepaalde gemeenskap 


\section{N. J. J. Olivier}

bestaan) en kulturele universalia (wat deur alle individue en gemeenskappe nagejaag word, soos voortbestaan, eie denke of self-waarde en vryheid) gemaak moet word.

Fick (1979:186) erken dat daar wel kulturele universalia bestaan, maiar dat dit aan twee beperkings onderworpe is:

* die spesifikasies of kulturele manifestasies van sulke universele waardes verskil van sisteem tot sisteem; en

* die spesifieke inhoud van hierdie waardes mag verskillende posisies in die belangrikheidsorde hê.

- Laastens impliseer die "Development for what? "-vraag 'n soeke na vergeldende geregtigheid deur die onderontwikkelde lande. Volgens Fick (1979: 187 ) behels dit drie aspekte:

* kompensasie vir uitbuiting in die verlede tydens die koloniale tydperk;

*'n onmiddellike verandering van die ekonomiese stelsel tot hul voordeel; en

* die verkryging van 'n meer aanvaarbare en regverdige toekoms.

\section{MODERNE BENADERINGE}

Goulet (1977:14) is van mening dat ontwikkeling 'n proses is wat halfpad tussen totale indeterminisme en totale determinisme geleë is. Hy ontken dat alle sosiale veranderinge noodwendig ontwikkeling is, aangesien verandering ook in reeds ontwikkelde gemeenskappe plaasvind. Daarom ontken hy ook dat ontwikkeling noodwendig modernisering daarstel.

Hy maak 'n interessante onderskeid tussen twee katerorieë veranderingsprosesse:

- die eerste proses het betrekking op produksie, beheer oor die natuur, rasionale organisasie en tegnologiese effektiwiteit;

- die tweede proses het betrekking op mags- en ideologiese strukture. 
Ontwikkelde lande is syns insiens bereid om hulp ten opsigte van die eerste proses te gee, maar is nie bereid om mag en ideologiese heerskappy op dieselfde wyse oor te dra nie: ". . p power and ideological mastery are not to be transferred on the same terms and in the same manner as economic progress or scientific knowhow"' (Goulet, 1977:15).

Soos reeds vermeld, beklemtoon Goulet die etiese onderbou van die konsep ontwikkeling. $\mathrm{Na}$ sy mening behels ontwikkeling ekonomiese, sosiale, politieke en kulturele doelstellings. Ontwikkeling. beteken dus sowel die verlangde eindtoestand ("terminal concition") as die proses om daardie eindtoestand te bereik: "Development" . . . thus covers the entire gamut of changes by which a social system, with optimum regard for the wishes of individuals and sub-systematic components of that system, moves away from a condition of life widely perceived as unsatisfactory in some way toward some condition regarded as "humanly better" (Goulet, 1977:333).

Hy stel ten slotte die vraag of ontwikkeling kwantifiseerbaar is. In beginsel is dit nie die geval nie, sê hy; ontwikkeling moet geëvalueer word volgens die waardes wat die betrokke gemeenskap as noodsaaklik vir sy eie gesondheid en welsvn stel. Ontwikkeling kan dus as die volwassewording ("maturation"), vermensliking ("humanization") of kwalitatiewe verbetering ("qualitative ascent") van menslike gemeenskappe omskryf word (Goulet, 1977:333).

Hauser (1974) maak 'n onderskeid tussen wasdom (groei) en ontwikkeling. Laasgenoemde omvat veral politiese, sosiale en kulturele aspekte wat nie noodwendig hand aan hand met die ekonomiese ontwikkeling verloop nie. Ekonomiese ontwikkeling omvat volgens hom vier kenmerke:

- verhoging van die produksie;

- produktediversifikasie;

- verdelings van die produksiemiddele; en

- verbetering van die lewenstandaard van ten minste die grootste gedeelte van die bevolking.

Castle (1972) aanvaar dat ontwikkeling nie net met ekonomiese aangeleenthede te maak het nie; hy stem met Curle saam dat ". . . an underdeveloped society is literaly an underdeveloped society not merely an underdeveloped economy (Castle, 1972:8). Toepaslike (intermediëre) tegnologie is 'n vereiste vir ontwikkeling en daar bestaan volgens hom vyf ontwikkelingsprioriteite (Castle, 1972:56-60): 


\section{N. J. J. Olivier}

- verlaging van die geboortesyfer;

- oplossing van die stad-platteland probleem;

- 'n radikale verbetering in die grondbesitstelsels;

- 'n aansienlike uitbreiding van die aantal arbeidsintensiewe projekte; en

- 'n meer doelbewuste toespitsing van opvoedkundige dienste op die basiese on twikkelingsbehoeftes.

Wallman (1977) wys daarop dat die basiese (oorspronklike) ontwikkelingsmodel evolusionêr van aard was, maar dat daar later 'n aantal ander modelle as reaksie daarteen na vore gekom het naamlik:

Die evolusionêre ontwikkelingsteorie: Hiervolgens toon ontwikkeling normaalweg 'n eenlynige en progressiewe opeenvolging. Nie-ontwikkeling kan toegeskryf word aan 'n gebrek aan materiële middele of aan die afwesigheid van nie-materiële ontwikkelingsvoorwaardes (soos byvoorbeeld gebrekkige organisasievermoë en ontoepaslike tradisionele strukture). Volgens hierdie benadering is ontwikkeling progressief, goed, normaal en voortdurend.

Die eindige ontwikkelingsteorie ("limits to growth model"): Hiervolgens plaas tenologies-ekologiese faktore (soos uitputting van die skaars middele)'n beperking op ontwikkeling. So 'n benadering is elitisties en selfbeskermend, en word uiteraard voorgestaan deur mense wat reeds nie meer die etiket "onderontwikkeld" dra nie.

Die eerste "dubbelsinnige" ontwikkelingsteorie ("development of underdevelopment model"): Hierdie teorie vertoon ooreenkomste met die vorige een, maar die politiesekonomiese verhoudinge word ter verklaring van die dichotomie ontwikkeldheid - onderontwikkeldheid aangewend. Dit hang dus saam met die reeds bespreekte afhanklikheidsteoric. Volgens dié benadering is dit die internasionale sisteem wat vir nie-ontwikkeling verantwoordelik is. Die middele nodig vir ontwikkeling word van die armes onttrek of ontneem met die gevolg like nie-ontwikkeling van eersgenoemde. Sommige teoretici beskou hierdie gevolg bloot as outomaties, terwyl ander dit as doelbewus kenmerk. Volgens dié benadering kan ontwikkeling slegs deur middel van massiewe politiesekonomiese manipulasies geskied. Hierdie siening word dan vandag ook sterk deur die Marixistiese ontwikkelingsteoretici aangehang.

Die tweede "dubbelsinnige" ontwikkelingsteorie: Waar die voorafgaande 'n globale (wêreldwye) verklaring vir die dichotomie ontwikkeldheid - onderontwikkeldheid probeer bied, werk hierdie teorie met kleiner eenhede en poog 


\section{Die Konsep Ontwikkeling}

dit om plaaslike teenstelinnge te verklaar. 'n Onderskeid word gemaak tussen ontwikkeling (iets positiefs) - wat verhoogde koopkrag en 'n hoër lewenstandaard (maar tot nadeel van ontwikkeling) impliseer. Voorbeelde van modernisering is welsynsuitbetalings, toerisme en oorbetalings deur trekarbeiders wat elders werk. Ontwikkeling vind dus nog steeds in die verwyderde metropolitaanse sentrum plaas. Modernisering sluit volgens hierdie benadering ontwikkeling uit.

Ontwikkeling impliseer volgens Wallman (1977:11-13) twee tipes progressie: 'n progressie na voldoening aan basiese behoeftes, en 'n progressie na groter outonomie en outentisiteit van die individu en/of die nasic. Hierdie aspek kan ook as die outonomie- en ontwikkelingsdichotomie omskryf word.

Ontwikkeling implıseer egter nie net positiewe aspekte nie. Wallman (1977: 13-14) onderskei drie "verliese" naamlik:

- waar aspirasies te hoog gestel was en daar nie onmiddellik of in die afsienbare toekoms daaraan voldoen kan word nie;

- waar individue of groepe relatief tot ander individue of groepe verliese ly; ontwikkeling as ekonomiese groei impliseer 'n verskerpte differensiasie in lewenstylverbetering; en

- die verlies wat daarin geleë is dat individue en goepe aan die ekonomiese ontwikkeling deel wil hê en tog nog onafhanklik en - soos in die verlede op sigself aangewese wil wees.

Mair (1975) wys daarop dat Neo-Marxiste en ander ontwikkelingsteoretici saamstem dat huidige ontwikkelingsbeleidsrigtings werkloosheid veroorsaak en nie genoeg gedoen het om armoede te verlig nie. Sy verwys na die Marxistiese siening dat alle ontwikkelingsteenstellinge aan die hand van klasse-analise verklaar moet word; volgens hierdie teorie is die uitbuitende klasse wêreldwyd verenig; die regerings van die onderontwikkelde lande is afhanklik van die ryk kapitaliste, en daarom kan slegs ' $n$ werkersrewolusie die situasie verander (vergelyk hier byvoorbeeld Kay (1975:1-12). Volgens De Kadt (1974:4-9) het die NecMarxistiese sosiologiese benadering twee uitgangspunte wat (tot onlangstoe) nie deur die atropoloë en sosioloë van die Neo-Klassieke skool gedeel is nie: die belang van klasse-analise en die strukture van afhanklikheid ("structures of dependence") op globale en op regionale vlak. 


\section{N. J. J. Olivier}

Ten slotte kan daar nog verwys word na die interessante tipologie van Bohnet (1974). Hy onderskei tussen:

ekonomiese ontwikkelingsteorie ë, waaronder

teorieë van die sosio-ekonomiese, tegnologiese en regionale dualisme

strategieteorieë, waaronder

die teorie van die ongelykwigtige groei (Hirchman) wat die uitbou van enkele sleutelindustrieë beoog;

die teorie van die ontwikkelingspole (Perroux) wat deur 'n regionale konsentrasie van beleggings 'n groei-effek wil bereik;

Die sogenaamde "Bigh push"-teorie (Rosenstein-Rodan) waarvolgens 'n groot beleggingstoot die nie-groei tot selfdraende groei en wasdom sal verander;

die teorie van die kritiese minimum (Leibenstein en Nelson) waarvolgens deur middel van 'n doelgerigte kapitaalinspuiting 'n hoër groei as die bevolkingsgroei bewerkstellig word en sodoende dalende inkomste en gepaardgaande dalende beleggings teen te gaan; en

die teorie van die gelykwigtige groei (Nurske) - wat in teenstelling met bogenoemde - daarvan uitgaan dat 'n samebundeling van komplementêre beleggings in alle sektore noodsaaklik is.

buitelandse bandelsteorië̈ wat in die wêreldekonomiese dominasie-afhanklikheidsverhouding die ontwikkelingshindernisse sien;

demografiese ontwikkelingsteorie $\ddot{e}$ wat die bevolkingsaanwas as ontwikkelingspolitiese kernprobleem beskou;

klimatologiese (biopolitiese) teorie $\ddot{e}$ wat die ekonomiese agterstand in die tropiese gebiede aan klimatologiese faktore toeskryf;

sosiologiese en psigoligiese teorië̈ (moderniseringsteorië̈) wat evolusionêre of spronggewyse verandering van tradisionaliteit na moderniteit as uitgangspunt aanvaar; en 
Die Konsep Ontwikkeling

Marxistiese teorie ë wat as uitgangspunt aanvaar dat die onderontwikkeldheid en strukturele wanontwikkeling deur koloniale indringing en uitbuiting veroorsaak wou wees en deur die na-koloniale wêreldarbeidsverdeling tussen nywerheids- en ontwikkelingslande (sogenaamde onderontwikkelde lande) voortgesit word.

\section{SAMEVATTING}

Uit bogenoemde uiteensetting is dit duidelik dat daar geen algemeen aanvaarde definisie van ontwikkeling bestaan nie. Ook 'n algemene teorie waarbinne ontwikkelingsprogramme ontwerp kan word, ontbreek.

Een van die belangrikste ontwikkelinge op die gebied van ontwikkelingsteorie was die prysgawe van die positivisties-behavioralistiese en anti-historiese benadering tot ontwikkeling tydens die sestigerjare ten gunste van 'n betrokke (relevante) post-behavioralistiese ontwikkelingsbeskouing waarin waarde-oordcle 'n kardinale plek inneem. 'n Tweede ontwikkeling (sedert die laat sestigerjare) was die toename in neo-Marxistiese standpunte wat onderontwikkeldheid bloot aan kapitalistiese eksploitasie (wat slegs deur revolusie herstel sou kon word) toeskryf.

Die veranderinge wat ten opsigte van die konsep ontwikkeling ingetree het, word goed geillustreer in die verwerping van die benadering "food for one is food for all" ten gunste van die siening dat "one man's meat may be the other man's poison". Hierin lê die oorgang aan 'n universalistiese na 'n gerelativeerde ontwikkelingsbenadering wat op waarde-oordele gebaseer is, opgesluit. Hierdie oorgang blyk ook duidelik uit die verwerping van die aanvanklike neoimperialistiese siening dat die "American way of life" die eindideaal vir alle ontwik keling is ten gunste van die benadering dat die VSA se ontwik kelingshulp slegs op "improving the lives of the poorest of the people" gerig behoort te wees. Ontwikkeling behels dus ten minste twee komponente:

- die begeerde einddoel (Goulet se "terminal condition") soos geformulecr deur die bewindhebbers; en

- metodes om bogenoemde te bereik.

Ontwikkeling is 'n dinamiese proses waarin gemeenskapsverandering die prominente rol speel. Dié proses van gemeenskapsverandering het implikasies op 


\section{N. J. J. Olivier}

die kulturele, sosiale, juridiese en ekonomiese samelewingsvlakke en dit het 'n sneeubaleffek: die vermoë tot bewerkstelliging van die verandering word verhoog na mate die proses vorder. Gemeenskapsverandering impliseer 'n tweeledigheid: gemeenskaps- en sosio-kulturele ontwikkeling (ten opsigte van byvoorbeeld die onderwys, die sosiale struktuur en die kwaliteit van menslike verhoudinge). Deelname aan hierdie gemeenskapsontwikkeling kan op georganiseerde en/of spontane wyse geskied. Passmore (1971:52-54) wys daarop dat populêre deelname aan en betrokkenheid by plaaslike aangeleenthede 'n aanvaarde element van gemeenskapsontwikkeling is.

In hierdie verband moet daar nog na ontwikkelingsbeplanning (die beplanningsperspektief wat die reëls voorsien waarvolgens ontwikkeling moet plaasvind) verwys word. Volgens Katz (1966:4-10) kan daar vyf dimensies onderskei word:

- doelgerigte beplanning;

- beplanning moet op handeling (aksie) gerig wees (dit behels die vermoë om die beplanning te laat realiseer);

- die bestaan van 'n keuse tussen alternatiewe. (Hier kan vier groepe keusekriteria onderskei word: wenslikheid, konsekwentheid, uitvoerbaarheid en optimaliteit);

- inagneming van die tydsperspektief; en

- dat beplanning ' $n$ proses is. Dit behels twee komponente: formulering en uitvoering.

'n Voorvereiste om ontwikkeling te laat slaag, is om eie waarde-oordele vanuit die betrokke gemeenskap - deur middel van deelname aan die beplanning én uitvoering van die ontwikkelingsprogramme - as bepaler van die verlangde persepsie van verhoging van lewenskwaliteit te laat dien. Toepaslike tegnologie en gerigte onderwys sal uitersard helangrike metodes in gemeenskapsontwikkeling moet wees.

Geslaagde ontwikkeling sal waarskynlik sosiale geregtigheid, die verligting van armoede, die ombouing of vervanging van strukture en politieke en ekonomiese onafhanklikheid ten gevolg hê. Differensiasie en individualisering op ekonomiese en sosiale gebied sal ook uit 'n ontwikkelingsituasie voortvloei. 


\section{Die Konsep Ontwikkeling}

Ontwikkeling behels dus die verhoging van die lewenskwaliteit van die individu en van die groep, en die vermensliking van die samelewing, dit wil sê " to do more, to know more, to have more, in order to be more".

\section{BIBLIOGRAFIE}

BALDWIN, R. E. 1972. Economic development and growth. 2nd ed. New York: Wilev.

CASTLE, E. B. 1972. Education for self-help: new strategies for developing countries London: Oxford University Press.

DE KADT, E. \& WILliAMS, G. , eds. 1974. Sociology and development. London: Tavistock Publications.

FICK, J. C. 1979. Contemporary trends and issues in the theory of development. Politikon, 6(2): 172-192.

GOULET, D. 1971. The cruel choice: a new concept in the theory of development. New York: Atheneum.

KATZ, S. M. 1966. A systems approach to development administration: a framework for analyzing capacity of action for national development. Washington: Comparative Administration Group, American Society for Public Administration.

KAY, 1975. Development and underdevelopment: a Marxist analysis.

LA PALOMBARA, J. .1971. Political science and the engineering of national development (In Palmer, M. \& Stern, L. eds. Political development in changing societies London: Lexington, Mass, Heath Lexington Books).

MAIR, L. 1975. Development. Man, 10(1):607.

MARITZ, C. J. 1980. Ontwikkeling binne plurale samelewings. Koers, 45(2): 158-180.

NOHLEN, D. \& NUSCHELEER, F. , Hrsg. 1974. Handbuch der Dritten Weit. Band 1. Hamburg: Hoffmann und Campe.

PASSMORE, G. C. 1971. Theoretical aspects of local government and community action Salisbury: Dept. of Political Science, Univ. of Rhodesia.

RIGGS, F. W. 1963. Bureaucrats and political developments: a proradoxical view. (In La Palombara, J. G. , ed. Bureaucracy and political development. Princeton; N. J. Princeton University Press).

ROSTOW, W. W. 1971. Stages of economic growth: A non-communist manifesto. 2nd ed. Cambridge: University Press.

WAllmaN, S. , ed. 1977. Perception of development. Cambridge: Cambridge University Press. 